\title{
Squamous Cell Carcinoma as an Important Differential Diagnosis of Erosive Pustular Dermatosis of the Scalp
}

\author{
Seyed Kaveh Fattahi ${ }^{1 *}$, Detlef Becker ${ }^{2}$ and Beate Weidenthaler-Barth ${ }^{3}$ \\ ${ }^{1,2}$ University of Mainz, department of dermatology \\ ${ }^{3}$ Dermato Histologie, Internationales Diploma in Dermatopathology, University of Mainz, department of dermatology
}

Received: August 16, 2017; Accepted: September 06, 2017; Published: September 21, 2017

*Corresponding author: Seyed Kaveh Fattahi, University of Mainz, department of dermatology, Tel: 00496131172903; Fax: 00496131173499; E-mail: kaveh.fattahi@unimedizin-mainz.de

\begin{abstract}
Erosive Pustular Dermatosis of the Scalp (EPDS) is a rare inflammatory disorder with unknown etiology characterized by pustules, erosions, and crusted lesions on the scalp. The diagnosis is based on the clinical and histological presentation. In addition, Squamous Cell Carcinoma (SCC) should be considered as an important differential diagnosis. A 78-year-old man presented with crusted, nonhealing, pruritic scalp lesions and erosions that had been occurring for 6 months. He was referred to us with suspected SCC, which could be excluded by multiple biopsies.
\end{abstract}

The clinical and histopathological features led us to the diagnosis of erosive pustular dermatosis of the scalp. The patient was treated with $10 \%$ salicylic ointment, topical and systemic antibiotics and topical steroids. The clinical condition promptly clears under this therapy.

Keywords: Erosive pustular dermatosis of the scalp; squamous cell carcinoma;

\section{Abbreviation}

Erosive pustular dermatosis of the scalp: EPDS

Squamous cell carcinoma: SCC

\section{Introduction}

Erosive Pustular Dermatosis of the Scalp (EPDS) is a rare skin disease with nonspecific clinical and histopathological findings. The pathogenesis is not well known, but some predisposing factors such as local trauma, topical retinoid acid or fluorouracil, varicella zoster and prolonged exposure of a bald scalp to UV light have been reported [1,2]. The clinical findings usually consist of pustules, erosions, and crusted lesions on the scalp. An appropriate clinical presentation and compatible histological pattern are required to diagnose the patient with EPDS. Possible clinical differential diagnoses are Squamous Cell Carcinoma (SCC), perifolliculitis abscedens et suffodiens, folliculitis decalvans, dermatitis artefacta, pyogenic granuloma, IgA pemphigus, tinea, pustular psoriasis and cicatricial pemphigoid [1-3]. Although the histological pattern is non-specific, biopsies are required to exclude severe differential diagnoses, especially SCC. This rare skin disease is more common in the elder population and affects more females than males [2,3]. It is difficult to treat and tends to relapse.

\section{Case reports}

A 78-year-old man presented pruritic crusted lesions on the scalp for 6 months. Treatment with different topical cortisone preparations was unsatisfactory. He had a previous history of hypertension, syringomyelia and spinal stenosis. Mild leukocytosis $(10.2 / \mathrm{nl})$ and elevated C-reactive protein $(23 \mathrm{mg} / \mathrm{l})$ were observed. Tests for electrolytes as well renal and hepatic parameters were normal. Physical examination showed several crusted lesions and erosions on the scalp (Figure 1).

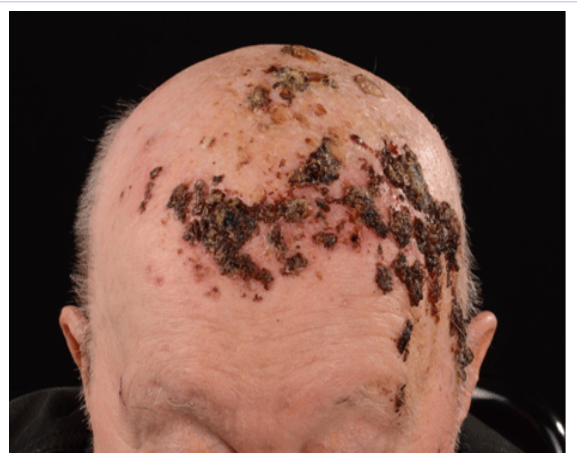

Figure 1: Clinical aspect on the first visit

At first, squamous cell carcinoma was suspected and skin biopsies were taken. This differential diagnosis was excluded by histological examination.

By microbiological examination Staphylococci (coagulase negative) were found, whereas fungal cultures were negative.

Histology from the scalp showed ulcerations with scalecrusting and superficial edema. In the dermis there were diffuse mixed cell infiltrates composed of lymphocytes, granulocytes and plasma cells. In the deep dermis scarring was seen (Figure 2). Another biopsy revealed narrowed epidermis overlying moderate mixed cell infiltrates in the dermis with exocytosis of inflammatory cells and scarring (Figure 3). Periodic Acid-Schiff 
(PAS) stain was negative for mycological organisms. Direct immunofluorescence was negative for IgG, IgM, IgA and C3 depositions.

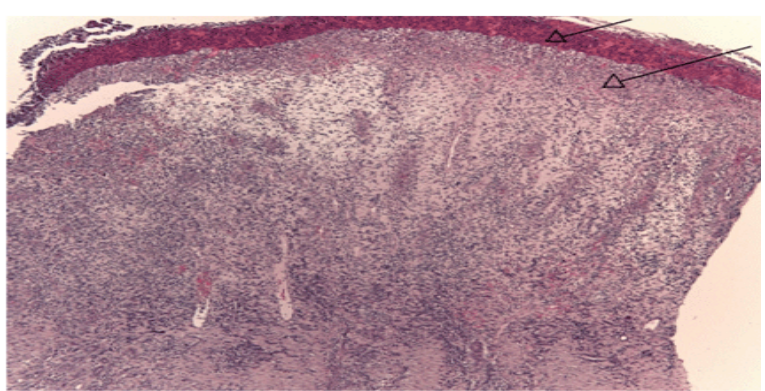

(a)

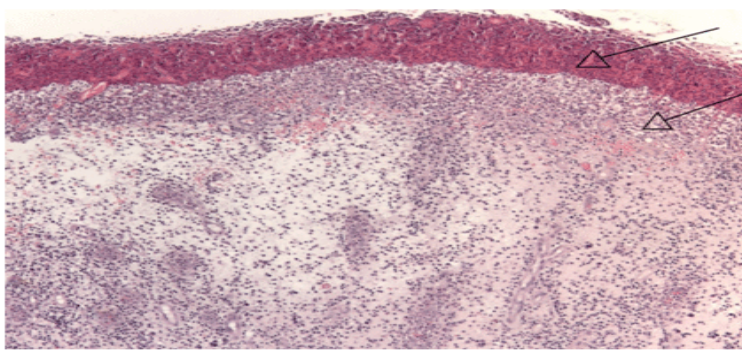

(b)

Figure 2 a,b: Ulceration with scale-crusting and diffuse mixed cell infiltration (x100).

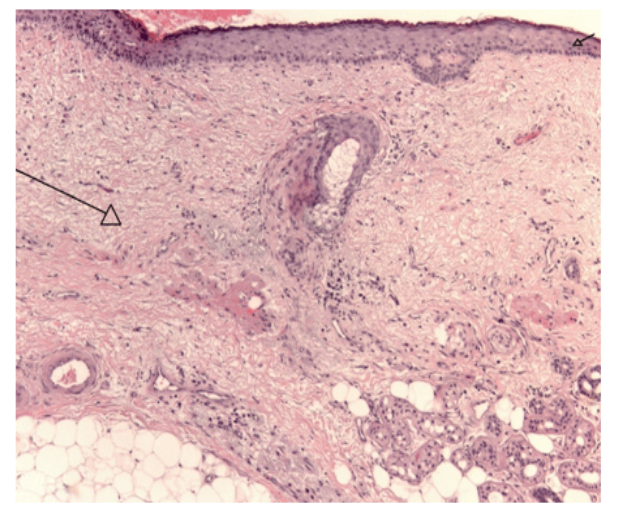

Figure 3: Narrowed epidermis overlying dermal scarring (x100).

The treatment was started with $10 \%$ salicylic acid and Aureomycin (chlortetracycline) ointment, and then continued with topical cortisone (Advantan) in association with antiseptic spray (Octenisept). Erosions were treated by antiseptic gel (polyhexanide gel) and Adaptic (wound dressing). In addition Augmentin 875/125 mg (amoxicillin and clauvulanate) was given as oral therapy twice daily. This resulted in improvement after 2 weeks.

\section{Discussion}

EPDS is a rarely reported disease. The etiology and exact pathogenesis of EPDS is unclear, but several predisposing factors have been reported such as scalp surgery, cryotherapy, radiotherapy, topical retinoid acid or fluorouracil, varicella zoster and prolonged exposure of a bald scalp to UV light [4].

The clinical presentation of EPDS consists of erosive, pustular, and crusted lesions resulting in scarring alopecia. The number of pustules can vary remarkably, and in some cases they are not present [5,3].

Upon histological examination, parakeratosis, hyperkeratosis, epidermal atrophy, inflammatory infiltrates, and occasional subcorneal pustules may be found [6,7]. Although the histopathology is non-specific, biopsies are obligatory to exclude severe differential diagnoses [5].

The clinical differential diagnosis includes squamous cell carcinoma, perifolliculitis abscedens et suffodiens, folliculitis decalvans, dermatitis artefacta, pyogenic granuloma, IgA pemphigus, Tinea, pustular psoriasis and cicatricial pemphigoid [7-9].

A number of patients with EPDS have previous squamous cell carcinoma of the skin. This severe differential diagnosis of EPDS has to be excluded carefully by skin biopsies [10].

The treatment of EPDS is difficult. Various treatments such as topical corticosteroids, topical and systemic antibiotics, topical calcipotriol or tacrolimus, oral isotretinoin, dapsone and zinc with various responses have been reported. Application of topical corticosteroids was shown to be effective, though relapses after discontinuation may occur $[5,7,11,12]$.

After exclusion of other differential diagnoses, the clinical and histopathological findings led us to the diagnosis of erosive pustular dermatosis of the scalp in our patient. The treatment was started with $10 \%$ salicylic acid for cleaning the crusted areas. After that continued with topical and systemic antibiotics in association with antiseptic spray as well as topical corticosteroid. A complete resolution of the condition under therapy confirmed our diagnosis.

The result of this study showed that EPDS can be misdiagnosed with squamous cell carcinoma, which may result in mistreatment and unintended adverse events.

\section{References}

1. Caputo R, Veraldi S. Erosive pustular dermatoses of the scalp. J Am Acad Dermatol. 1993;28(1):96-98.

2. Vano-Galvan A, Martorell-Catayud A, Pedro J. Erosive pustular dermatosis of the scalp. J Pak Med Assoc. 2012;62(5):501-502.

3. Patton D, Lynch PJ, Fung MA, Fazel N. Chronic atrophic erosive dermatosis of the scalp and extermities: A recharacterization of erosive pustular dermatosis. J Am Acad Dermatol. 2007;57(3):421427

4. Parodi A, Ciaccio M, Rebora A. Erosive pustular dermatosis of the scalp. Int J Dermatol. 1990;29(7):517-518.

5. Pye RJ, Peachey RD, Burton JL. Erosive pustular dermatosis of the scalp. Br J Dermatol. 1979;100(5):559-566.

6. Mastroianni A, Cota C, Ardigò M, Minutilli E, Berardesca E. Erosive pustular dermatosis of the scalp: a case report and review of the literature. Dermatology. 2005;211(3):273-276. 
7. Allevato M, Clerc C, del Sel JM, Donatti L, Cabrera H, Juárez M. Erosive pustular dermatoses of the scalp. Int J Dermatol. 2009;48(11):1213 1216.

8. Vaccaro M, Guarneri C, Barbuzza 0, Guarneri B. Erosive pustular dermatosis of the scalp: an uncommon condition typical of elderly patients. J Am Geriatr Soc. 2008;56(4):761-762. doi: 10.1111/j.15325415.2008.01615.x

9. Vaccaro M, Barbuzza O, Guarneri B. Erosive pustular dermatosis of the scalp following treatment with topical imiquimod for actinic keratosis. Arch Dermatol. 2009;145(11):1340-1341. doi: 10.1001/ archdermatol.2009.278
10. Wantz M, Perceau G, Goeldel AL, Grange F, Bernard P. Erosive pustular dermatoses of the legs. Ann Dermatol Venereol. 2011;138(2):9399. doi: 10.1016/j.annder.2011.01.003

11. Guarneri C, Vaccaro M. Erosive pustular dermatosis of the scalp following topical methylaminolaevulinate photodynamic therapy. J Am. Acad Dermatol. 2009;60(3):521-522. doi: 10.1016/j. jaad.2008.09.006

12. Peterson B0, Bygum A. Erosive pustular dermatosis of the scalp: a case treated successfully with Isotretinoin. Acta DermVenereol. 2008;88(3):300-330. doi: 10.2340/00015555-0416 